\title{
The Influence of Structural Parameters on the Reactivity of Model Complexes for Compound II: A Mini Review
}

\author{
Dorota Rutkowska-Zbik • Agnieszka Drzewiecka-Matuszek • \\ Malgorzata Witko
}

Published online: 8 April 2014

(c) The Author(s) 2014. This article is published with open access at Springerlink.com

\begin{abstract}
The present brief review aims at elucidation of the parameters affecting the properties and reactivity of high valent iron(IV) oxo porphyrin complexes, being models of compound II reactive intermediate known from biochemistry of cytochromes and peroxidases. The stress is put on the influence of the axial ligand and porphyrin ring substituents, with special attention on implications for their catalytic activity.
\end{abstract}

Keywords Compound II (Cpd II) - Oxidation ·

Bio-mimetic catalysis

\section{Introduction}

Heme moiety, a naturally occurring iron porphyrin, constitutes an active site of numerous enzymes, whose main functions include binding and transport of gases, electron transfer and catalysis. Biochemical studies show that the heme active group exhibit different reactivity, depending on its immediate surrounding [1, 2]. A number of factors are usually invoked which determine the activity of heme proteins, such as axial ligation (often referred to as proximal groups), presence of aminoacids inside a distal pocket (which may participate in binding, activation and transformation of substrates), substrate binding sites etc. [3-5].

Further, the activity of the heme group in catalysis is strictly related to the ability to transform its central ion into so-called high-valent species with an oxo ligand $(=\mathrm{O})$

D. Rutkowska-Zbik ( $₫) \cdot$ A. Drzewiecka-Matuszek $\cdot$ M. Witko Jerzy Haber Institute of Catalysis and Surface Chemistry, Polish Academy of Sciences, ul. Niezapominajek 8, 30-239 Krakow, Poland

e-mail: nczbik@cyf-kr.edu.pl attached. The oxidation reaction comprises then a transfer of the oxo ligand to the substrate and an acceptance of electrons by the electron-deficient iron ion. For a long time, the highest reactivity was ascribed to iron(IV)-oxo cation radical porphyrin species, called compound I (Cpd I) [6-17]. Only recently, its one electron reduced form, iron(IV)-oxo porphyrin (compound II, Cpd II-see Fig. 1), has been proved to play a similar role in catalytic reactions, in particular in activation of $\mathrm{C}-\mathrm{H}$ bond [18-20]. It should be born in mind that when the reactivity of model complexes for the reactive intermediates in hemoprotein catalysis was compared (hydroperoxo iron(III) porphyrin-Cpd 0, Cpd I and Cpd II), Cpd II appeared the most efficient in hydride-transfer [21].

The elucidation of structure-activity relationship for high-valent iron-oxo species was considerably accelerated by the ability to synthesize their mimics. Model studies in solution facilitated determination of parameters, which are the most relevant for their action in enzymatic systems. The first syntheses of Cpd II mimics were reported in early 1980s [22, 23]. The addition of a nitrogen base ( $N$-methylimidazole, pyridine, piperidine) to the $\mu$-peroxo bis iro$\mathrm{n}$ (III) porphyrin [TmTPFe- $\left.\mathrm{O}_{2}-\mathrm{FeTmTP}\right]$ (TmTP_dianion of meso-tetra- $m$-tolylporphyrin) at $-80{ }^{\circ} \mathrm{C}$ in toluene solution resulted in the formation of $[\mathrm{BTmTPFe}(\mathrm{IV})=\mathrm{O}]$ species (B-nitrogen base), as proved by ${ }^{1} \mathrm{H}$ NMR and UV-VIS. The iron(IV)-oxo species might also be generated by addition of hydrogen peroxide to the iron(III) porphyrin complex-[meso-tetrakis(2,4,6-trimethyl-3sulfonatophenyl)porphinato]iron(III) hydroxide (tetrasodium salt) at $\mathrm{pH} 10.0$ in buffered aqueous solution [24]. It was proved that $\mathrm{Fe}(\mathrm{IV})=\mathrm{O}$ porphyrins might also be obtained through electrochemical oxidation of porphyrin, although the main product was $\mathrm{Fe}(\mathrm{IV})=\mathrm{O}$ porphyrin cation radical, Cpd I mimic [25]. Since then, other poprhyrin substrates have been used to yield synthetic Cpd II mimics 


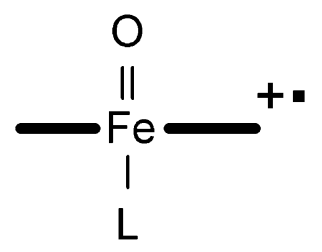

Cpd I

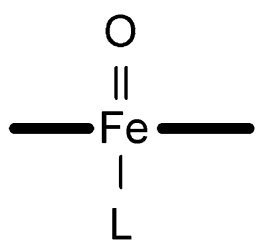

Cpd II
Fig. 1 Schematic view of Cpd I and Cpd II

[26], allowing for their physico-chemical characterization and further studies of their reactivity.

Following the experimental findings, theoretical investigations of the molecular mechanisms of oxygenations by high valent oxo-iron complexes concern mostly Cpd I systems (see e.g. $[8,14,27-30]$ ), while studies of the reactivity of Cpd II models are rather scarce [31-33] and mostly focus on the reactivity of cytochromes, in which the central iron ion is coordinated by a thiolate ligand from cysteine. The structure and reactivity of high valent ironoxo species has been already reviewed, but the main stress is always put on the Cpd I parameters [8, 34-36].

Our aim, therefore, is to investigate how parameters of the synthetic models for Cpd II, in particular porphyrin ring substitution and type of axial ligand, affect their structure and reactivity. Our motivation arises from the fact that the physical parameters of Cpd II determine its catalytic activity, especially in $\mathrm{C}-\mathrm{H}$ bond activation in hydroxygenation and dehydrogenation processes [37].

\section{Influence of Axial Ligand on Parameters of Cpd II Model Complexes}

It appears that the main structural difference in heme enzymes is connected with the nature of an amino acid coordinated in the proximal position to the iron(III) center in the active site (i.e. tyrosine for catalases, histidine for peroxidases and cysteine for cytochrome P450). Consequently, the model experimental and theoretical studies focused mostly on elucidation of the influence of the axial ligand on the structure and hence catalytic reactivity of iron porphyrins (Fig. 2). In the first instance, they aimed at understanding the activity of hemoproteins.

Antony et al. [38] studied the influence of the axial ligand $\left(\mathrm{Cl}^{-}, \mathrm{Im},-\mathrm{SCH}_{3}\right)$ on the structural parameters of high-valent iron oxo intermediates as models of active species in chloroperoxidases, peroxidases and cytochromes P450, respectively. Their theoretical DFT-LDA calculations performed within SCC-X $\alpha$ method showed that the charge and spin density distribution in the $\mathrm{Fe}(\mathrm{IV})=\mathrm{O}$ group are insensitive on the type of axial ligand. However, axial ligation affects the polarity of the $\mathrm{Fe}(\mathrm{IV})=\mathrm{O}$ fragment.

More recently, Sun et al. [33] investigated a series of neutral $\mathrm{N}$-donor ligands (imidazole, pyridine and their derivatives) as ligands in $[(\mathrm{L}) \mathrm{PFe}(\mathrm{IV})=\mathrm{O}]$ by means of DFT-B3LYP method. Their conclusions supported earlier observation that axial ligation resulted in the weakening of the $\mathrm{Fe}(\mathrm{IV})=\mathrm{O}$ bond expressed by the elongation of $\mathrm{Fe}(\mathrm{IV})=\mathrm{O}$ distance and movement of $\mathrm{Fe}$ ion into the porphyrin plane.

The obtained results were rationalized in terms of the electrophilic parameters of the chosen axial ligands consisting of a series of substituted pyridines with groups of varying Hammet constants. The comparison revealed that when the electron-withdrawing ability of the axial ligand was increased, the $\mathrm{Fe}(\mathrm{IV})=\mathrm{O}$ bond became shorter [33]. At the same time, the Fe-axial ligand was elongated. Both changes resulted in the decrease of the $\mathrm{Fe}(\mathrm{IV})=\mathrm{O}$ bond strength.

Additionally, the $\mathrm{Fe}(\mathrm{IV})=\mathrm{O}$ electron density in complexes with axial ligands were lower than in the fivecoordinate $[\mathrm{PFe}(\mathrm{IV})=\mathrm{O}]$. In such a way the electron density
Fig. 2 Influence of the type of axial ligand on the parameters of Cpd II models

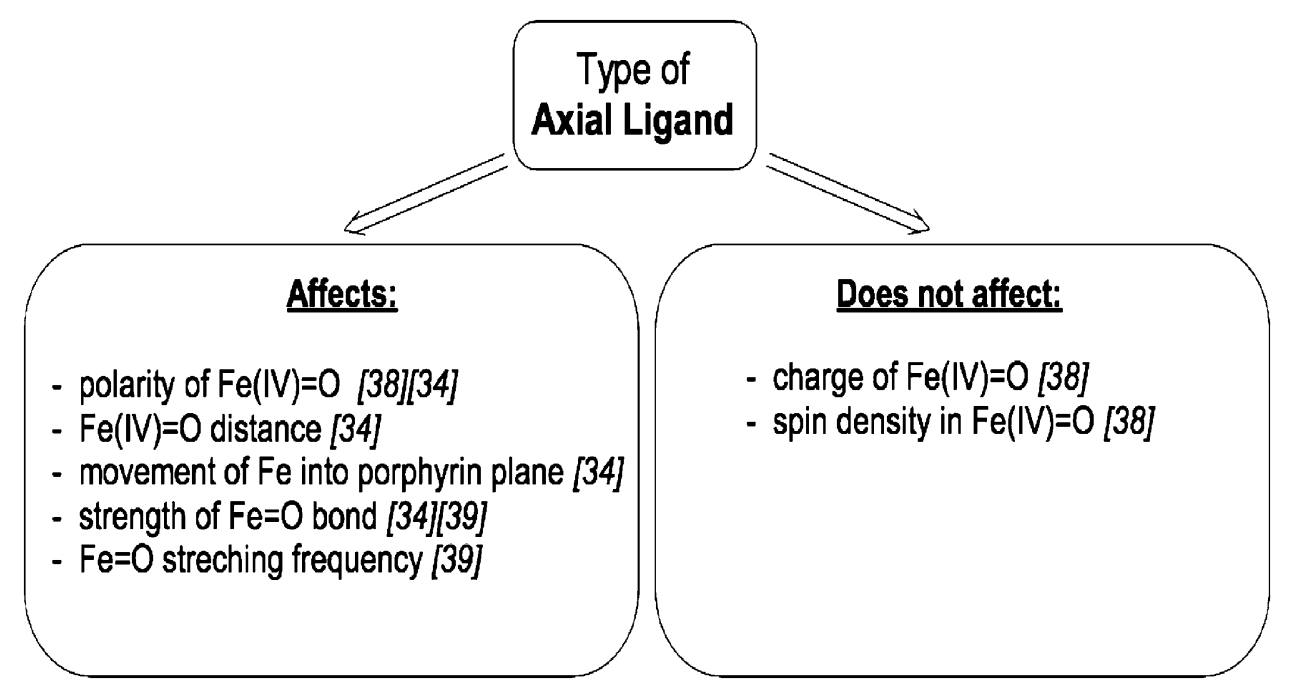


Fig. 3 Changes in reactivity of Cpd II models caused by axial ligation

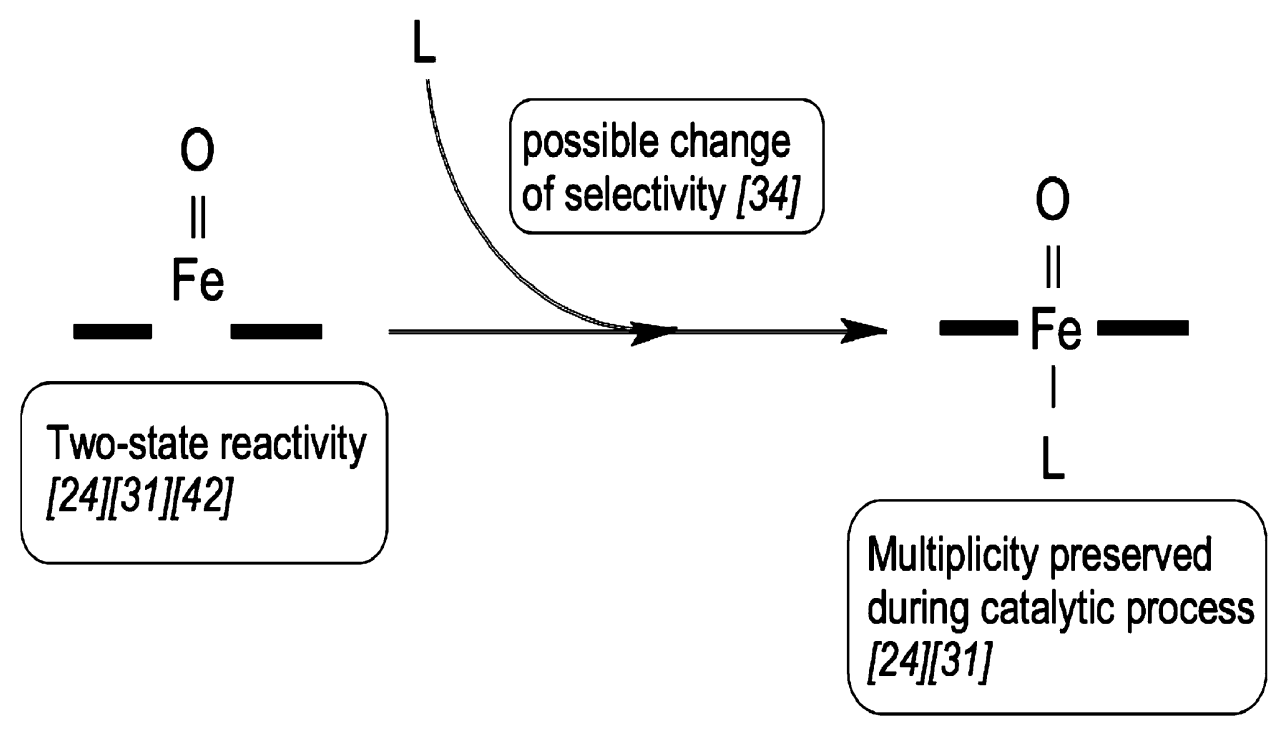

was shifted from oxygen to iron ion and the porphyrin ligand and $\mathrm{Fe}(\mathrm{IV})=\mathrm{O}$ bond became less polar.

This finding confirmed conclusions from the earlier experimental studies by Gold et al. [39], in which a series of $[(\mathrm{L})(\mathrm{TPP}(2,6-\mathrm{Cl})) \mathrm{Fe}(\mathrm{IV})=\mathrm{O}]$ complexes $(\mathrm{TPP}(2,6-\mathrm{Cl})$ dianion of mezo-tetrakis-2,6 dichlorophenyl porphyrin) with axial ligands being solvent molecules of tetrahydrofuran, dimethylformamide or 1-methylimidazole. They demonstrated that the strengthening of Fe-axial ligand bond weakened the $\mathrm{Fe}(\mathrm{IV})=\mathrm{O}$ bond. The effect was ascribed either to a trans effect or by movement of the iron ion toward the porphyrin plane.

Finally, the strengthening of the Fe-axial ligand bond results also in the decrease of $\mathrm{Fe}(\mathrm{IV})=\mathrm{O}$ stretching frequency, as shown by resonance Raman spectra [38].

\subsection{Implications for Catalysis}

The above mentioned studies showed that the changes in axial ligation of model Cpd II complexes influence the $\mathrm{Fe}(\mathrm{IV})=\mathrm{O}$ group, mostly its length and polarity (see Fig. 2). It is of no surprise that this change would be reflected in the rate and mechanism of reactions, which they catalyse.

In order to asses the differences in the reactivity of Cpd II models two concurrent catalytic processes (epoxidation and dehydrogenation of 1,3-cyclohexadiene) were studied for complexes with different axial ligands (none, imidazole, pyridine, 4-amino-pyridine, and 4-nitryl pyridine) with DFT/B3LYP method [33]. The selectivity of the reaction may be switched upon ligation, as shown by comparing the barriers of the rate-determining steps of both processes. The un-ligated system clearly favoured epoxidation, whereas dehydrogenation and epoxidation were practically equally probable (the barriers for dehydrogenation and epoxidation were within the error limit of the performed calculations) - see Fig. 3. As the axial ligand was varied, the barrier heights were quite small (differences in energies amounted to 3.6 and $3.3 \mathrm{kcal} / \mathrm{mol}$ for dehydrogenation and epoxidation, respectively), suggesting only minor axial ligand effect on the reactivity of Cpd II mimics. The longer $\mathrm{Fe}(\mathrm{IV})=\mathrm{O}$ bond was (and the more electron-withdrawing substituent in axial ligand), the larger both barriers were, but the changes were not very pronounced, as mentioned earlier.

Similar conclusions were drawn from a Car-Parinello molecular dynamics (within B3LYP and BP86) investigation of $\mathrm{O}-\mathrm{H}$ bond cleavage in $\mathrm{OOH}^{-}$by $\mathrm{Cpd}$ II, where active sites of peroxidases and catalases were modelled as $[(\mathrm{L}) \mathrm{PFe}-\mathrm{OH}]$ species $(\mathrm{L}$-imidazole or phenolate interacting with arginine, respectively) [40]. The energy barriers for $\mathrm{O}-\mathrm{H}$ abstraction were invariant in respect to the axial ligand. One should note, however, that the active site in this study consisted of iron-hydroxo group, as is often postulated for peroxidases [41].

Moreover, there is no significant influence of the nature of the axial ligand on the reactivity of Cpd II mimic in oxidations of 4-methoxybenzyl alcohol and 4-methoxybenzaldehyde, as confirmed both by theoretical (DFT with B3LYP) and experimental kinetic studies [24].

Another important aspect of the catalytic reaction was brought about by theoretical considerations on methane hydroxylation [31]. In the comparative study, two Cpd II models were employed: $[\mathrm{PFe}(\mathrm{IV})=\mathrm{O}]$ and $[(\mathrm{SH}) \mathrm{PFe}(\mathrm{IV})=\mathrm{O}]^{-}$. It was shown that the un-ligated $\mathrm{Cpd}$ II model exhibited so called two-state reactivity model (TSR)-it underwent spin-crossing along the reaction pathway. While the starting state was triplet, the $\mathrm{C}-\mathrm{H}$ bond activation proceeded on the quintet surface. The presence of the axial ligand altered the reactivity, so that the system 
did not change multiplicity and stayed on the triplet surface (compare Fig. 3). Two state reactivity mechanism was also postulated to operate during cyclohexane oxidation to adypic acid by $[\mathrm{PFe}(\mathrm{IV})=\mathrm{O}]$, as studied by DFT with B3LYP functional [42].

The detailed analysis of the Cpd II mimic frontier orbitals [31] revealed that $\mathrm{C}-\mathrm{H}$ bond activation in $\mathrm{CH}_{4}$ may proceed through both $\pi$ - and $\sigma$-attack on [PFe(IV) $=\mathrm{O}$ ], the latter mechanism was excluded for axially ligated $[(\mathrm{SH}) \mathrm{PFe}(\mathrm{IV})=\mathrm{O}]^{-}$. Finally, it was shown that the apparent reaction barrier for $\mathrm{C}-\mathrm{H}$ abstraction was lower for the unligated system. This finding showed inversed trend as compared with the results of the $\mathrm{H}$-abstraction from 1,3cyclohexadiene, where the process was facilitated by the presence of the axial ligand [33]. The difference may arise from the different character of the axial ligands, as the neutral ones were investigated for dehydrogenation of 1,3cyclohexadiene, as opposed to the negatively charged $\mathrm{SH}^{-}$ studied in the context of $\mathrm{CH}_{4}$ hydroxylation.

\section{Influence of Porphyrin Substituents on Cpd II}

The studies of the influence of the heme substitution on the reactivity of hemeproteins (see e.g. [3] and references therein) are the foundation of the analogous studies in model systems. It follows from the statement that the electron density on the iron ion is related to the basicity of the pyrrolic nitrogen atoms of the porphyrin, which, in turn, depends on the structure and substituents of the porphyrin ligand [43].

Nam and co-workers showed that the oxidizing power of high-valent oxo porphyrin species may be adjusted by altering the electronic nature of the porphyrin ligand. In particular, an electron-deficient $[\mathrm{TPFPPFe}(\mathrm{IV})=\mathrm{O}]$ (TPFPP-dianion of meso-tetrakis(pentafluorophenyl)) complex was shown a reactivity comparable to that of Cpd I model [44].
The recent catalytic results on the hydroxylation of xantene by a model high valent iron oxo systems obtained from [(4-TMPyP)Fe] (4-TMPyP-dianion of meso-tetrakis( $N$-methyl-4-pirydinium porphyrin) by Bell and Groves [45] suggested that the meso-substitution in porphyrin ligand influenced the $\sigma$-donor properties of the coordinating pyrrole nitrogen atoms. They, in turn, affected the energies of the frontier orbitals of the Cpd II complex. It was postulated that this may tune the catalytic performance, as demonstrated for the model manganese systems [46].

Indeed, kinetic studies on the oxygenation of alkenes and benzylic alcohols by a series of chlorinated meso-tetrakis-phenylporphyrins were performed [47], which enabled a further insight into the macrocycle structure relation on parameters characterizing Cpd II models. The measured rate constants for oxidation reactions revealed that the more electron withdrawing substituents on the porphyrin ring, the lower catalytic activity of the examined complexes. This finding was rationalized taking into account the mechanism of the studied reactions. They were initiated by the disproportionation of Cpd II mimics into Cpd I and resting state iron(III) systems. As the former were made responsible for the proper catalytic process, in this sense the cited studies indicated that meso-substitution of porphyrin ligand affected Cpd II electrochemical properties.

The electrochemical properties of different porphyrin complexes, including high-valent iron-oxo species were studied by Fukuzumi [48]. Theoretical studies based on Marcus theory related redox properties of Cpd II to the planarity of the macrocycle, which is known to depend on the presence of porphyrin ring substituents (see Fig. 4) [49, 50].

Fukuzumi [48] demonstrated that the stronger binding of iron with the non-planar porphyrin upon electrochemical Fe oxidation, a larger bond reorganization energy and,
Fig. 4 Influence of the type of porphyrin substituents on the parameters of Cpd II models

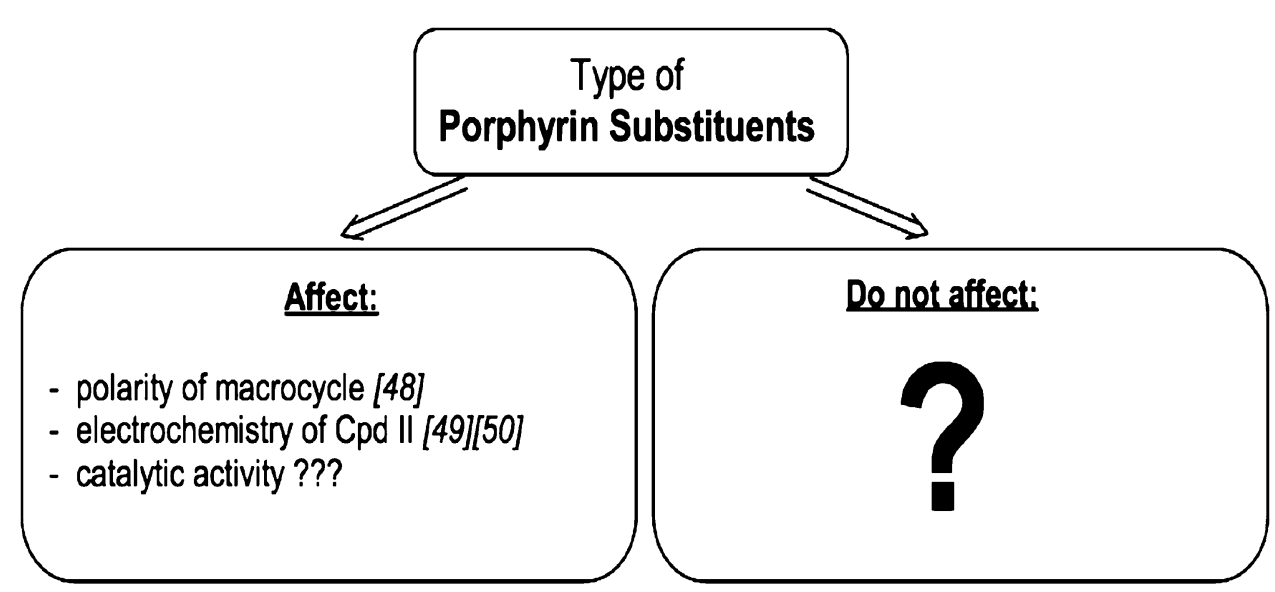


consequently, a slower electron-transfer rate as compared with the planar porphyrin.

One should note that the planarity of the centre of the complex is also induced by axial ligation, as described earlier.

As is seen, further studies are needed, both by experiment and theory, to investigate in depth the reactivity pattern of Cpd II models based on substituted porphyrins.

\subsection{Influence of the Porphyrin Substitution on Catalytic Properties}

Little is known on the relation between the structure of the porphyrin ligand and the catalytic performance of a model Cpd II complex. The hydroxylation of alcohols and aldehydes by substituted porphyrin species, refereed to in the above paragraph, were in fact catalysed by Cpd I mimics [47]. Their results shed light on the electrochemical parameters of $\mathrm{Cpd}$ II, but gave little hint as to the $\mathrm{C}-\mathrm{H}$ bond activating ability of the employed oxidants.

Up to our knowledge, theoretical considerations of the dependence of reaction pathways, in particular selectivity and reactivity of Cpd II models with varying porphyrin substituents, are not known. The reason for this is probably two-fold. On the one hand, taking into account full porphyrin ligand, with all peripheral groups, would be too computationally demanding for current DFT applications, due to the size of the model. On the other hand, the reactivity studies are still mostly focused on Cpd I mimics, as the prominent reactive species. As already mentioned, catalysis by Cpd II gained new interest only within the last years. Within the short time limit, however, both obstacles will hopefully be overcome giving insight into the relationship between the porphyrin ligand structure and catalytic performance of model Cpd II systems, e.g. through application of hybrid QM/MM (quantum mechanics/ molecular mechanics) methods.

\section{Conclusions}

It is believed that for a given substrate the performance of any catalyst may be improved by a proper choice of its composition and structure. In case of porphyrin-based systems, this may be achieved by changing the macrocycle ring substituents or the metal axial ligand.

Review of the literature data on the influence of the axial ligand on the structural parameters of the Cpd II mimic revealed that the stronger $\mathrm{Fe}$-axial ligand bond, the weaker the $\mathrm{Fe}(\mathrm{IV})=\mathrm{O}$ one. The source of this effect laid either in the trans effect or is due to the insertion of the iron ion in the porphyrin plane.
The mechanistic studies of the reactions catalysed by Cpd II mimics with varying axial ligands demonstrated that the type of axial ligand has only subtle, if any, effect on their reactivity.

More importantly, there is a pronounced impact of ligation as such on catalytic performance of the systems examined thus far. First of all, the two-state reactivity mechanism came into play in un-ligated systems and the change between triplet and quintet multiplicity surfaces were observed. What is more, the presence (or absence) of the axial ligand may switch the reactivity, if more than one reaction pathway is possible.

Incomplete data on the effect of porphyrin ring substituents exist, not allowing for the exhaustive description of the interplay between their presence and the type on the structure and activity of Cpd II models. One may learn, however, that the meso-substituents modify the $\mathrm{Fe}(\mathrm{IV})=\mathrm{O}$ bond electronically, i.e. by influencing the donating properties of the pyrrolenine nitrogen atoms and sterically, i.e. disturbing the planarity of the central part of the complex.

In conclusion, we hope that future will bring more data which will supplement our rather limited knowledge about factors determining reactivity of the model Cpd II complexes. We believe that this may only be achieved by a synergy between theory and experiment, which enable more thorough, complementary studies of the reactivity parameters of high-valent iron-oxo species.

Acknowledgments The authors would like to acknowledge the financial support from the Ministry of Science and Higher Education within the project Iuventus Plus [2010-2011] IP2010 036270 and from the Leading National Research Centre KNOW through Marian Smoluchowski scientific consortium, Krakow.

Open Access This article is distributed under the terms of the Creative Commons Attribution License which permits any use, distribution, and reproduction in any medium, provided the original author(s) and the source are credited.

\section{References}

1. Dunford HB (2010) Peroxidases and catalases: biochemistry, biophysics, biotechnology and physiology. Wiley, Hoboken

2. Mayfield JA, Dehner CA, DuBois JL (2011) Recent advances in bacterial heme protein biochemistry. Curr Opin Chem Biol 15(2):260-266. doi:10.1016/j.cbpa.2011.02.002

3. He B, Sinclair R, Copeland BR, Makino R, Powers LS, Yamazaki I (1996) The structure function relationship and reduction potentials of high oxidation states of myoglobin and peroxidase. Biochemistry 35(7):2413-2420

4. D'Antonio J, Ghiladi RA (2011) Reactivity of deoxy- and oxyferrous dehaloperoxidase B from Amphitrite ornata: identification of compound II and its ferrous-hydroperoxide precursor. Biochemistry 50(27):5999-6011. doi:10.1021/bi200311u

5. Gumiero A, Murphy EJ, Metcalfe CL, Moody PC, Raven EL (2010) An analysis of substrate binding interactions in the heme peroxidase enzymes: a structural perspective. Arch Biochem Biophys 500(1):13-20. doi:10.1016/j.abb.2010.02.015 
6. van Eldik R (2007) Fascinating inorganic/bioinorganic reaction mechanisms. Coord Chem Rev 251:1649-1662

7. Denisov IG, Makris TM, Sligar SG, Schlichting I (2005) Structure and chemistry of cytochrome P450. Chem Rev 105:22532278

8. Meunier B, de Visser SP, Shaik S (2004) Mechanism of oxidation reactions catalyzed by cytochrome P450 enzymes. Chem Rev 104:3947-3980

9. Newcomb M, Hollenberg PF, Coon M (2003) Multiple mechanisms and multiple oxidants in P450-catalyzed hydroxylations. J Arch Biochem Biophys 409:72-79

10. Pan Z, Zhang R, Newcomb M (2006) Kinetic studies of reactions of iron(IV)-oxo porphyrin radical cations with organic reductants. J Inorg Biochem 100:524

11. Bell SR, Groves JT (2009) A highly reactive P450 model compound I. J Am Chem Soc 131:9640-9641

12. Nam W, Goh YM, Lee YJ, Lim MH, Kim C (1999) Inorg Chem 38:3238-3240

13. Goh YM, Nam W (1999) Significant electronic effect of porphyrin ligand on the reactivities of high-valent iron(IV) oxo porphyrin cation radical complexes. Inorg Chem 38:914-920

14. Song WJ, Ryu YO, Song R, Nam W (2005) Oxoiron(IV) porphyrin pi-cation radical complexes with a chameleon behavior in cytochrome P450 model reactions. J Biol Inorg Chem 10:294-304

15. Gross Z (1996) The effect of axial ligands on the reactivity and stability of the oxoferryl moiety in model complexes of Compound I of heme-dependent enzymes. J Biol Inorg Chem 1:368-371

16. Gross Z, Nimri S (1994) A pronounced axial ligand effect on the reactivity of oxoiron(IV) porphyrin cation radicals. Inorg Chem 33:1731-1732

17. Gross Z, Nimri S, Barzilay CM, Simkhovich L (1997) Reaction profile of the last step in cytochrome P-450 catalysis revealed by studies of model complexes. J Biol Inorg Chem 2:492-506

18. Groves JT, Gross Z, Stern MK (1994) Preparation and reactivity of oxoiron(IV) porphyrins. Inorg Chem 33:5065-5072

19. Jeong YJ, Kang Y, Han A-R, Lee Y-M, Kotani H, Fukuzumi S, Nam W (2008) Hydrogen atom abstraction and hydride transfer reactions by iron(IV)-oxo porphyrins. Angew Chem Int Ed 47:7321-7324

20. Nam W, Park S-E, Lim IK, Lim MH, Hong J, Kim J (2003) First direct evidence for stereospecific olefin epoxidation and alkane hydroxylation by an oxoiron(IV) porphyrin complex. J Am Chem Soc 125(48):14674-14675

21. Fertinger C, Hessenauer-Ilicheva N, Franke A, van Eldik R (2009) Direct comparison of the reactivity of model complexes for compounds 0, I, and II in oxygenation, hydrogen-abstraction, and hydride-transfer processes. Chem Eur J 15:13435-13440

22. Chin D-H, Balch AL, La Mar GN (1980) Formation of porphyrin ferryl $\left(\mathrm{FeO}_{2}+\right)$ complexes through the addition of nitrogen bases to peroxo-bridged iron(III) porphyrins. J Am Chem Soc 102(4):1446-1448. doi:10.1021/ja00524a051

23. Chin D-H, La Mar GN, Balch AL (1980) Role of ferryl $\left(\mathrm{FeO}_{2}+\right)$ complexes in oxygen atom transfer reactions. Mechanism of iron(II) porphyrin catalyzed oxygenation of triphenylphosphine. J Am Chem Soc 102(18):5945-5947. doi:10.1021/ja00538a059

24. Oszajca M, Drzewiecka-Matuszek A, Franke A, Rutkowska-Zbik D, Brindell M, Witko M, Stochel G, van Eldik R (2014) Mechanistic insight into peroxo-shunt formation of biomimetic models for compound II, their reactivity toward organic substrates and the influence of N-methylimidazole axial ligation. Chem Eur J 20:2328-2343. doi:10.1002/chem.201303694

25. Groves JT, Gilbert JA (1986) Electrochemical generation of an iron(IV) porphyrin. Inorg Chem 25(2):123-125. doi:10.1021/ ic00222a003

26. Balch AL, Chan YW, Cheng RJ, La Mar GN, Latos-Grazynski L, Renner MW (1984) Oxygenation patterns for iron(II) porphyrins.
Peroxo and ferryl (FeIVO) intermediates detected by proton nuclear magnetic resonance spectroscopy during the oxygenation of (tetramesitylporphyrin)iron(II). J Am Chem Soc 106(25): 7779-7785. doi:10.1021/ja00337a022

27. Shaik S, Devesh K, de Visser SP, Altun A, Thiel W (2005) Theoretical perspective on the structure and mechanism of cytochrome P450 enzymes. Chem Rev 105:2279-2328

28. de Visser SP (2006) Differences in and comparison of the catalytic properties of heme and non-heme enzymes with a central oxo-iron group. Angew Chem Int Ed Engl 45(11):1790-1793. doi:10.1002/anie.200503841

29. de Visser SP, Fo Ogliaro, Sharma PK, Shaik S (2002) What factors affect the regioselectivity of oxidation by cytochrome P450? A DFT study of allylic hydroxylation and double bond epoxidation in a model reaction. $J$ Am Chem Soc 124(39):11809-11826. doi:10.1021/ja026872d

30. Shaik S, Kumar D, de Visser SP (2008) A valence bond modeling of trends in hydrogen abstraction barriers and transition states of hydroxylation reactions catalyzed by cytochrome P450 enzymes. J Am Chem Soc 130:10128-10140

31. Rosa A, Ricciardi G (2012) Reactivity of compound II: electronic structure analysis of methane hydroxylation by oxoiron(IV) porphyrin complexes. Inorg Chem 51(18):9833-9845. doi:10. 1021/ic301232r

32. Tahsini L, Bagherzadeh M, Nam W, de Visser SP (2009) Fundamental differences of substrate hydroxylation by high-valent iron(IV)-oxo models of cytochrome P450. Inorg Chem 48(14):6661-6669. doi:10.1021/ic900593c

33. Sun Y, Hu X, Li H, Jalbout AF (2011) Comparison between the two different forms of iron(IV)-oxo porphyrin and the effects of neutral axial ligand on their catalysis: a theoretical study. Comput Theor Chem 966(1-3):62-69

34. Hohenberger J, Ray K, Meyer K (2012) The biology and chemistry of high-valent iron-oxo and iron-nitrido complexes. Nat Commun 3:720. doi:10.1038/ncomms 1718

35. Balcells D, Clot E, Eisenstein O (2010) C-H bond activation in transition metal species from a computational perspective. Chem Rev 110:749-823. doi:10.1021/cr900315k

36. Fujii H (2002) Electronic structure and reactivity of high-valent oxo iron porphyrins. Coord Chem Rev 226:51-60

37. Krest CM, Onderko EL, Yosca TH, Calixto JC, Karp RF, Livada J, Rittle J, Green MT (2013) Reactive intermediates in cytochrome p450 catalysis. J Biol Chem 288(24):17074-17081. doi:10.1074/jbc.R113.473108

38. Antony J, Grodzicki M, Trautwein AX (1997) Local density functional study of oxoiron(IV) porphyrin complexes and their one-electron oxidized derivatives. axial ligand effects. J Phys Chem A 101(14):2692-2701

39. Gold A, Jayaraj K, Doppelt P, Weis R, Chottard G, Bill E, Ding X, Trautwein AX (1988) Oxoferryl complexes of the halogenated (Porphinato)iron Catalyst: (Tetrakis(2,6-dichlorophenyl)porphinato)iron. J Am Chem Soc 110:5756-5761

40. Vidossich P, Alfonso-Prieto M, Rovira C (2012) Catalases versus peroxidases: DFT investigation of $\mathrm{H}(2) \mathrm{O}(2)$ oxidation in models systems and implications for heme protein engineering. J Inorg Biochem 117:292-297. doi:10.1016/j.jinorgbio.2012.07. 002

41. Gumiero A, Metcalfe CL, Pearson AR, Raven EL, Moody PC (2011) Nature of the ferryl heme in compounds I and II. J Biol Chem 286(2):1260-1268

42. Noack H, Georgiev V, Blomberg MR, Siegbahn PE, Johansson AJ (2011) Theoretical insights into heme-catalyzed oxidation of cyclohexane to adipic Acid. Inorg Chem 50(4):1194-1202. doi:10.1021/ic101405u

43. Orzeł Ł, Kania A, Rutkowska-Żbik D, Susz A, Gy Stochel, Fiedor L (2010) Structural and electronic effects in the metalation 
of porphyrinoids. Theory and experiment. Inorg Chem 49(16): 7362-7371. doi:10.1021/ic100466s

44. Nam W, Park S-E, Lim IK, Lim MH, Hong J, Kim J (2003) First direct evidence for stereospecific olefin epoxidation and alkane hydroxylation by an oxoiron(IV) porphyrin complex. J Am Chem Soc 125(48):14674-14675. doi:10.1021/ja0368204

45. Bell SR, Groves JT (2009) A highly reactive P450 model compound I. J Am Chem Soc 131(28):9640-9641

46. Balcells D, Raynaud C, Crabtree RH, Eisenstein OE (2008) A Rational Basis for the Axial Ligand Effect in C-H Oxidation by $[\mathrm{MnO}($ porphyrin $)(\mathrm{X})]+(\mathrm{X}) \mathrm{H} 2 \mathrm{O}, \mathrm{OH}-, \mathrm{O} 2-)$ from a DFT Study. Inorg Chem 47(21):10090-10099. doi:10.1021/ic8013706
47. Pan Z, Newcomb M (2007) Kinetics and mechanism of oxidation reactions of porphyrin-iron(IV)-oxo intermediates. Inorg Chem 46(16):6767-6774

48. Fukuzumi S (2013) Electron-transfer properties of high-valent metal-oxo complexes. Coord Chem Rev 257(9-10):1564-1575. doi:10.1016/j.ccr.2012.07.021

49. Szaleniec M, Tokarz-Sobieraj R, Witko M (2008) Modification of tetraphenylporphyrin ring in manganese(III) complexes-theoretical description of the influence on their physicochemical properties. Pol J Chem 82:1853-1863

50. Kadish KM, Smith KM, Guilard R (2000) The porphyrin handbook. Academic Press, San Diego 